\section{Gut gerüstet}

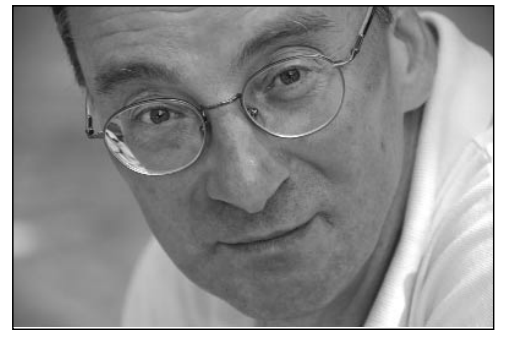

Foto: Petra Schmucker, Frankfurt am Main
Prognosen seien schwierig, besonders wenn sie die $\mathrm{Zu}$ kunft beträfen, lautet ein Karl Valentin zugeschriebenes Bonmot. Und der österreichische Managementlehrer
Fredmund Malik verfügt deshalb auch strikt: Realistisches Management stütze sich nicht auf Prognosen, weil niemand die Zukunft vorhersehen könne. Dennoch müssen sich Verantwortliche von Unternehmen und Organisationen ein Bild der zu erwartenden Entwicklung der nächsten Zeit machen. Nur so können sie handeln und ihre Mitarbeiterinnen und Mitarbeiter führen.

Die wahrscheinlichen Entwicklungslinien für die allgemeine Zukunft von Organisationen lassen sich in drei Megatrends zusammenfassen: erstens die Umstellung der hierarchischen Ordnung zur Netzwerkorganisation; zweitens die Verlagerung der Führung von der Spitze zu den Rändern, die mit ihrer Umwelt in direktem Kontakt stehen; drittens die Umstellung von der auf schriftlicher Aufzeichnung beruhenden Organisation zu einem elektronisch basierten Gefüge mit tiefgreifenden Folgen für den Alltag von Unternehmen.

So gesehen sind Wohlfahrtsverbände bestens präpariert für die Zukunft: Die Branche besteht aus hundertausenden Einheiten aller Größen und die »Wohlfahrtsriesen " können gar nicht anders als ihre rechtlich selbstständigen Mitgliedsorganisationen durch das geduldige Weben von Netzwerken bei der Stange zu halten. Durch den tagtäglichen Kontakt mit gesellschaftlicher Realität erfahren soziale Dienste und Einrichtungen frühzeitig, was sich ändert und wo neue Antworten gefragt sind. Und entgegen aller Unkenrufe herrscht bei Fachkräften der Sozialen Arbeit eine große Sensibilität für den dramatischen Wandel von der Bürokratie zum digitalen Zeitalter, von der Akte zum USB-Stick.

Vielleicht kann eine Überlegung des amerikanischen Computerwissenschaftlers Alan Kay eine Ermutigung für die Wohlfahrtsverbände bieten: Die beste Art, die Zukunft vorauszusagen, sei: die Zukunft selbst zu erfinden.

Gerhard Pfannendörfer - Chefredaktion -

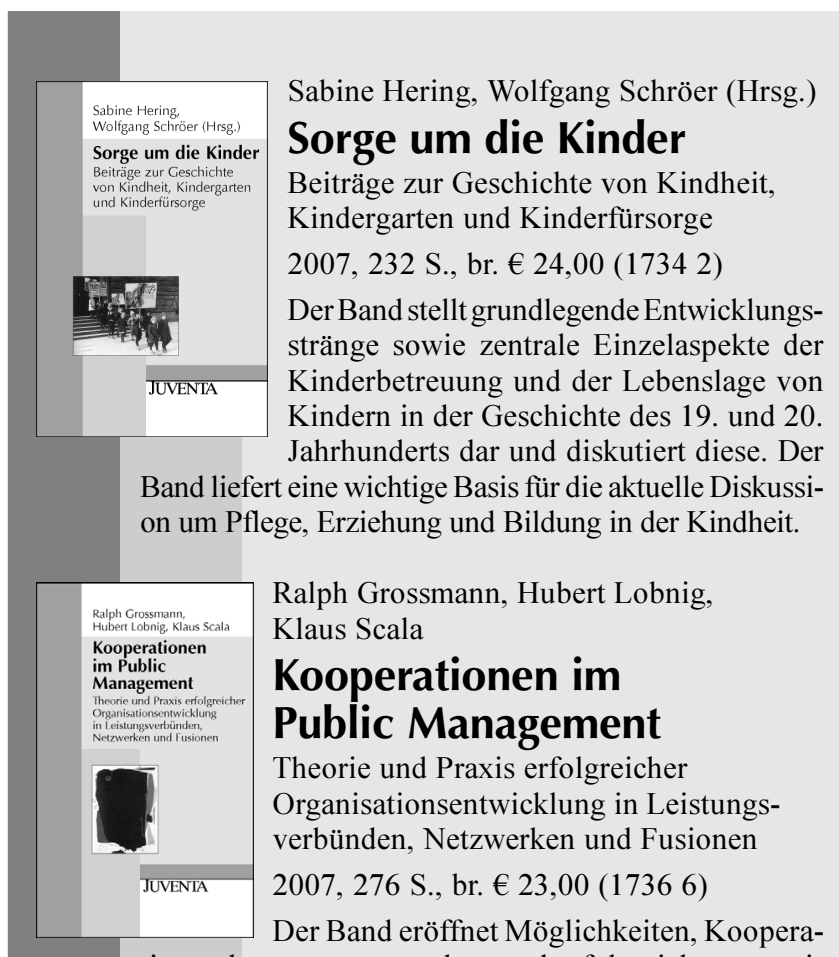
tionen bewusst zu gestalten und erfolgreich zu entwickeln. Er bietet durch Praxiserfahrungen, Fallbeispiele und Theorie eine grundlegende Orientierung für Manager und Beraterinnen von Kooperationen.

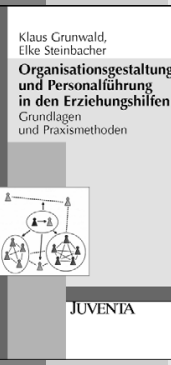

Klaus Grunwald, Elke Steinbacher Organisationsgestaltung und Personalführung in den Erziehungshilfen Grundlagen und Praxismethoden Basistexte Erziehungshilfen, hrsg. im Auftrag der Internationalen Gesellschaft für erzieherische Hilfen (IGfH). 2007, 260 S., br. $€ 18,00$ (1778 6)

Der vorliegende Band führt fachbezogen in zentrale Themen des Sozialmanagements ein und stellt methodische Hilfsmittel für die Bewältigung des Arbeitsalltags in Führungspositionen zur Verfügung.

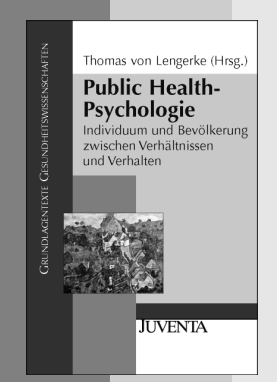
Thomas von Lengerke (Hrsg.) Public Health-Psychologie Individuum und Bevölkerung zwischen Verhältnissen und Verhalten Grundlagentexte Gesundheitswissenschaften, hrsg. von P. Kolip. 2007, 260 S., br. $€ 19,50$ (1569 0)

Die Autoren entwickeln Konzepte und Ansätze zu drängenden Fragen der Verhaltensund Sozialepidemiologie, von Kontextfaktoren wie Arbeit, Kultur und Migration, des Empowerments und einer Sozialpsychologie sozialer und politischer Partizipation und Prozesse.

Mehr Info im Internet: http://www.juventa.de Juventa Verlag, Ehretstraße 3, D-69469 Weinheim

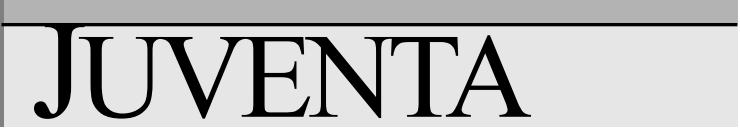

